\title{
Effect of Calcination on the Sintering of Gel-Derived, Zirconia-Toughened Alumina
}

\author{
Peter den Exter, ${ }^{\dagger}$ Louis Winnubst ${ }^{*,+}$ Theo H. P. Leuwerink, ${ }^{\dagger}$ and Anthonie J. Burggraaf
}

University of Twente, Faculty of Chemical Technology, Laboratory of Inorganic Chemistry, Materials Science and Catalysis, 7500 AE Enschede, The Netherlands

The densification behavior of $\mathrm{ZrO}_{2}\left(+3 \mathrm{~mol} \% \quad \mathrm{Y}_{2} \mathrm{O}_{3}\right) / 85$ wt $\% \mathrm{Al}_{2} \mathrm{O}_{3}$ powder compacts, prepared by the hydrolysis of metal chlorides, can be characterized by a transition- and an $\alpha$-alumina densification stage. The sintering behavior is strongly determined by the densification of the transition alumina aggregates. Intra-aggregate porosity, resulting from calcination at $800^{\circ} \mathrm{C}$, partly persists during sintering and alumina phase transformation and negatively influences further macroscopic densification. Calcination at $1200^{\circ} \mathrm{C}$, however, densifies the transition alumina aggregates prior to sintering and enables densification to almost full density $(96 \%)$ within $2 \mathrm{~h}$ at $1450^{\circ} \mathrm{C}$, thus obtaining a microstructure with an alumina and a zirconia grain size of $1 \mu \mathrm{m}$ and $0.3-0.4 \mu \mathrm{m}$, respectively.

\section{Introduction}

T HE mechanical properties of alumina ceramics can be improved by dispersing $15 \mathrm{wt} \%$ zirconia in the alumina matrix. ${ }^{1}$ The toughening mechanisms associated with zirconiatoughened alumina (ZTA) are related to the phase transformation from metastable tetragonal zirconia to the monoclinic form during cooling after sintering (microcrack toughening) or during mechanical loading (transformation toughening).

High strength and toughness require an optimized transformation-toughening mechanism. This can be achieved by sintering to dense, fine-grained ceramics with zirconia grain sizes less than the critical grain size for spontaneous transformation $(0.7 \mu \mathrm{m})^{2}$ and by further appiying postsintering heat treatments to obtain the proper fraction of transformable zirconia. An alumina grain $\leq 1 \mu \mathrm{m}$ after sintering has the added advantage of making hot forging possible as a postsintering heat treatment. ${ }^{3}$

A range of wet-chemical techniques have been reported for the preparation of zirconia-alumina ceramic powders ${ }^{4-10}$ which result in fine-grained transition alumina- $\left(\gamma-, \theta-\mathrm{Al}_{2} \mathrm{O}_{3}\right)$ containing powders with an intimate mixture of both zirconia and alumina. Transition aluminas are metastable and will transform to $\alpha$-alumina during sintering. In all methods mentioned above, pressure-assisted sintering techniques were necessary to obtain dense materials.

The concept of simultaneous sintering and phase transformation was first reported by Badkar and Bailey ${ }^{11}$ as an alternative processing route for the preparation of alumina ceramics. They observed a drastic decrease in densification rate upon the phase transformation to $\alpha$-alumina, because the transformation to

\footnotetext{
G. L. Messing-contributing editor
}

\footnotetext{
Manuscript No. 193931. Received December 27, 1993; approved February 7, 1994. Based on parts of the thesis submitted by P. den Exter for the Ph.D. degree, University of Twente, The Netherlands, 1991.

Partly supported by the Innovative Research Programme on Technical Ceramics (IOP-TK) with financial aid of the Dutch Ministry of Economic Affairs.

*Member, American Ceramic Society.

Presen address: Hoogovens Groep BV, IJmuiden, The Nerherlands.

Author to whom correspondence should be addressed
}

$\alpha$-alumina is a nucleation and growth process. The densification behavior can be improved by a close control of the nucleation kinetics by seeding ${ }^{12}$ or compaction. ${ }^{13}$ The relation between nucleation kinetics and sintering behavior has now been well established..$^{14,15}$

Literature strongly suggests that, apart from nucleation kinetics, a relation exists between the morphology of the transition alumina aggregates and the microstructural development during the phase transformation to $\alpha$-alumina. ${ }^{16}$ Although Dynys and Halloran ${ }^{17}$ extensively studied the relation between the presence of $\alpha$-alumina aggregates and the densification behavior, they did not take into consideration the morphology of the original transition alumina aggregates.

The aim of this paper is to investigate the influence of calcination temperature on the morphology of transition alumina aggregates and the sintering behavior of gel-derived ZTA compacts, and to establish the influence of zirconia on this part of the sintering process. In this way we expect to be able to obtain a microstructure after the alumina phase transformation, which provides a better opportunity for low-temperature sintering and optimum grain growth control than a more conventional approach on the basis of $\alpha$-alumina.

\section{Experimental Procedure}

\section{(1) Powder Preparation}

$\mathrm{ZrO}_{2}\left(+3 \mathrm{~mol} \% \quad \mathrm{Y}_{2} \mathrm{O}_{3}\right) / 85 \mathrm{wt} \% \quad \mathrm{Al}_{2} \mathrm{O}_{3}$ powders were prepared by the hydrolysis of a dilute solution $(0.8 M)$ of metal chlorides in $\mathrm{HCl}(0.2 M)$ by adding it slowly to a dispersion turbine reactor ${ }^{18}$ with a large excess of $\mathrm{NH}_{4} \mathrm{OH}$ (Merck, 25\%). The hydrous gel was washed nine times in water/ammonia mixtures ( $\mathrm{pH} \geq 11)$ to remove all of the chloride. Between each washing step, the gel was allowed to settle, after which the clear supernatant liquid was removed. The gel was filtered and wet-milled with ethanol in polyethylene bottles using Teflon balls. Subsequently the gel was washed three times with ethanol to remove free water. The gel was dried in air at $120^{\circ} \mathrm{C}$, dry-milled in a polyethylene bottle using Tefion balls, and calcined in air for 2 $\mathrm{h}$ at temperatures ranging from $550^{\circ}$ to $1300^{\circ} \mathrm{C}$ (heating rate $2.5^{\circ} \mathrm{C} / \mathrm{min}$ ) to examine the influence of the calcination temperature on the morphology of the transition alumina aggregates.

\section{(2) Characterization}

The chemical composition of the calcined powders was determined by X-ray fluorescence spectrometry (PW 1410 spectrometer, Philips, Eindhoven, Netherlands). The silicon content was determined by the method described by Kruidhof. ${ }^{19}$ Minor elements were determined by atomic absorption spectroscopy.

The phase composition of the powders was determined by $\mathrm{X}$-ray diffraction (PW $1710 \mathrm{X}$-ray diffractometer, Philips) with $\mathrm{Cu} K \alpha$ radiation. The temperature of the phase transformation to $\alpha$-alumina was measured in $\mathrm{N}_{2}$, at $2.5^{\circ} \mathrm{C} / \mathrm{min}$, by differential scanning calorimetry, (DSC 1500, Stanton Redcroft, London, U.K.) using $\alpha$-alumina as a reference. Crystallite size was determined from X-ray line broadening. The peak profiles of the 
(111)-reflection of both tetragonal zirconia (JCPDS-card 17923) and $\theta$-alumina (JCPDS - card 23-1009) and the (400)reflection of $\gamma$-alumina (JCPDS-card 10-425) were scanned stepwise (step size $/$ measuring time $=0.015^{\circ} / 10 \mathrm{~s}$ ) while the sample was rotated about the normal axis. The crystallite size was calculated using the Scherrer equation: ${ }^{20}$

$$
D=\frac{K \lambda}{\beta \cos (\theta)}
$$

where $D$ is the crystallite diameter, $\lambda$ is the wavelength of the radiation, $\theta$ is the diffraction angle, $K$ is a constant, and $\beta$ is the integral line width corrected for instrumental broadening and $K \alpha$ separation. The calculations were based on the width at half maximum instead of the integral line width. Therefore, $K$ was 0.94 . The crystallite size and shape were also determined by transmission electron microscopy (200 CT, JEOL, Tokyo, Japan).

The pore structures were derived from the shape of the nitrogen adsorption/desorption isotherms, measured at $-196^{\circ} \mathrm{C}$ after degassing at $300^{\circ} \mathrm{C}$ (ASAP 2400, Micromeritics, Norcross, GA). The specific surface area of the powders was determined by nitrogen adsorption, using the same equipment.

Powders were isostatically pressed (400 MPa) and pressureless sintered for $2 \mathrm{~h}$ at $1600^{\circ} \mathrm{C}$. Nonisothermal sintering behavior was investigated in a dilatometer $(402 \mathrm{E}$ dilatometer, Netzsch, Exton, PA) at $2.5^{\circ} \mathrm{C} / \mathrm{min}$. Bulk densities of the green and sintered compacts were determined in $\mathrm{Hg}$ by the Archimedes technique. The broadening of the $\mathrm{X}$-ray reflections did not justify an accurate calculation of the lattice parameters. All densities are therefore based upon the theoretical density of $\alpha$-alumina $\left(3.965 \mathrm{~g} / \mathrm{cm}^{3}\right)$ and yttria-stabilized tetragonal zirconia $\left(6.04 \mathrm{~g} / \mathrm{cm}^{3}\right)$. The theoretical densities of the composites were calculated using the equation

$$
\rho_{\mathrm{th}}=\frac{100}{\left(\frac{X}{3.965}\right)+\left(\frac{Y}{6.04}\right)}
$$

where $X$ and $Y$ are the amount of alumina and zirconia, respectively.

The ceramic microstructure of polished and thermally etched ceramics was examined by scanning electron microscopy (JSM-35CF scanning electron microscope, JEOL). Grain sizes were measured by the line intercept technique. ${ }^{21}$

\section{Results and Discussion}

\section{(1) Powder Properties}

The hydrolysis of metal chlorides and subsequent calcination yields a powder which meets the required bulk-chemical composition. After calcination, the ZTA powders contained $\approx 500$ ppm silicon, and the $\mathrm{K}_{2} \mathrm{O}, \mathrm{CaO}$, and $\mathrm{MgO}$ concentrations were less than $100 \mathrm{ppm}$. The $\mathrm{Fe}_{2} \mathrm{O}_{3}$ content was less than $300 \mathrm{ppm}$ and the $\mathrm{Na}_{2} \mathrm{O}$ content less than $200 \mathrm{ppm}$.

With increasing calcination temperature (Table I), the alumina crystallization sequence, starting from bayerite $\left(\mathrm{Al}(\mathrm{OH})_{3}\right)$ is

Table I. Characteristics of ZTA Powders after Calcination at

\begin{tabular}{|c|c|c|c|c|c|}
\hline \multirow{2}{*}{$\begin{array}{l}T_{\text {vidu }} \\
\left({ }^{\circ} \mathrm{C}\right)\end{array}$} & \multicolumn{2}{|c|}{ Phase composition } & \multirow{2}{*}{$\begin{array}{l}S_{\text {B.F }} \\
\left(\mathrm{m}^{2} / \mathrm{g}\right)\end{array}$} & \multicolumn{2}{|c|}{ Crysiallite size (nm) } \\
\hline & $\mathrm{Al}_{2} \mathrm{O}_{3}$ & $\mathrm{ZrO}_{2}$ & & $\mathrm{ZrO}_{2}$ & $\mathrm{Al}_{2} \mathrm{O}_{3}$ \\
\hline 120 & Bayerite & Amorph & & & \\
\hline 550 & $\gamma$ & Amorph & 254 & & \\
\hline 800 & $\gamma$ & Tetr & 126 & & 6 \\
\hline 900 & $\dot{\theta}$ & Tetr & 83 & & 6 \\
\hline 1000 & $\theta$ & Tetr/(monocl) & 71 & & \\
\hline 1100 & $\theta$ & Tetr & 55 & $42-44 *$ & $33-35^{*}$ \\
\hline 1200 & $\theta$ & Tetr/(monocl) & 32 & $33-48 *$ & $36-52^{*}$ \\
\hline 1300 & $\alpha$ & Tetr/(monocl) & 6 & & \\
\hline
\end{tabular}
Various Temperatures $\left(T_{\text {calc }}\right)$

*Measured on several powder batches.

$$
\text { Bayerite } \rightarrow \eta / \gamma-\mathrm{Al}_{2} \mathrm{O}_{3} \rightarrow \theta-\mathrm{Al}_{2} \mathrm{O}_{3} \rightarrow \alpha-\mathrm{Al}_{2} \mathrm{O}_{3}
$$

$\mathrm{X}$-ray diffraction could not clearly distinguish between $\eta$ - and $\gamma$-alumina, and thus they will be denoted as $\gamma$-alumina. In a pure alumina precursor, the transformation to $\alpha$-alumina normally takes place at approximately $1150^{\circ} \mathrm{C}^{13}$ In gel-derived ZTA, the transformation to $\alpha$-alumina is shifted toward a temperature above $1200^{\circ} \mathrm{C}$. Likewise, tetragonal zirconia is not observed by $\mathrm{X}$-ray diffraction until calcined at $800^{\circ} \mathrm{C}$. In a pure yttria-doped zirconia precursor, tetragonal zirconia is observed when calcined at $550^{\circ} \mathrm{C} .{ }^{18}$ Apparently, zirconia and alumina strongly affect each other, indicating an intimate mixture of the phases.

The aggregate structure of the powder, as observed by transmission electron microscopy, reflects the morphology frequently observed for transition aluminas ${ }^{16}$ and clearly consists of a stack of irregular alumina platelets with irregular slitshaped pores separating the platelets. According to Wefers and Misra, ${ }^{16}$ the actual structure of these pores is a combination of slit-shaped pores parallel to the $(001)$ cleavage plane of the alumina and a network of irregularly shaped slits perpendicular to the $(001)$ cleavage plane, thus giving rise to the irregularly shaped plate structure.

\section{(2) Green Microstructure}

A representative nitrogen adsorption-desorption isotherm on a ZTA compact, prepared from a powder calcined at $800^{\circ} \mathrm{C}$, is given in Fig. 1. The hysteresis loop in the relative pressure range of 0.6 to 0.8 , corresponding to a pore radius of $3 \mathrm{~nm}$, typically results from wedge-shaped capillaries with a closed edge at the narrower side, perpendicular to open slit-shaped capillaries with parallel walls.22 This type of hysteresis was also observed for the as-calcined powder and, thus, results from the intra-aggregate pore structure, as mentioned above.

The hysteresis loop, observed in the relative pressure range of 0.9 to 1.0 , is of the A-type of De Boer's classification of isotherms ${ }^{22}$ and corresponds to open capillaries with wide openings and narrow short necks and obviously results from interaggregate pores. Green compacts, prepared from powders calcined at a temperature $>1000^{\circ} \mathrm{C}$, have only A-type interaggregate pores, suggesting that the aggregates densified during calcination at a temperature somewhere between $1000^{\circ}$ and $1100^{\circ} \mathrm{C}$.

\section{(3) Densification Behavior}

Compacts prepared from powders calcined at temperatures ranging from $800^{\circ}$ to $1200^{\circ} \mathrm{C}$ sinter to almost full density within $2 \mathrm{~h}$ at $1600^{\circ} \mathrm{C}$ (Table II). Two separate densification stages can

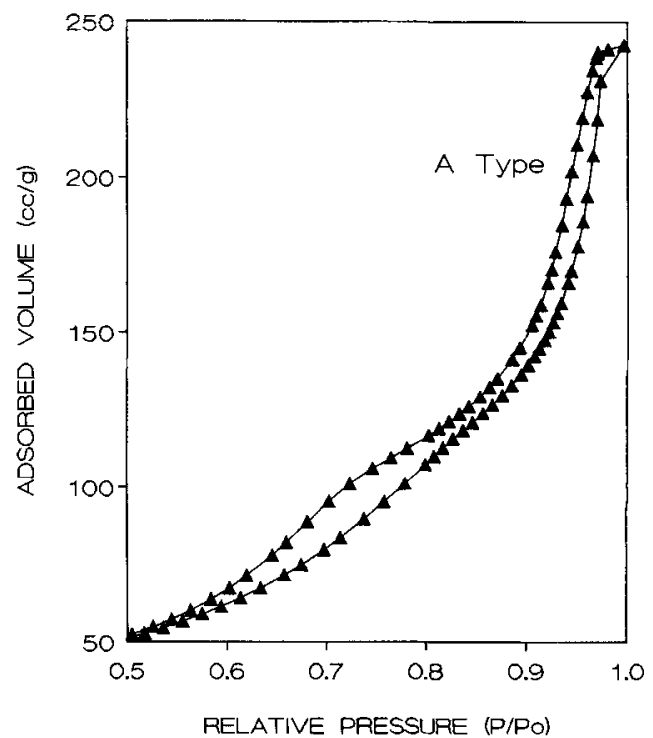

Fig. 1. Representative nitrogen adsorption-desorption isotherm on ZTA $\left(T_{\text {calc }}=800^{\circ} \mathrm{C}\right)$. 
be distinguished (Fig. 2). The drastic decrease in densification rate at $1250^{\circ} \mathrm{C}$ is most likely caused by grain growth accompanying the alumina phase transformation at this temperature. ${ }^{23}$ After the phase transformation, both compacts have a density of $51 \%$ of theoretical, as was calculated from the linear shrinkage.

The compact prepared from powder calcined at $1300^{\circ} \mathrm{C}$ contains $\alpha$-alumina and cannot be sintered to a high density within $2 \mathrm{~h}$ at $1600^{\circ} \mathrm{C}$ (see Table II). The concept of simultaneous sintering and phase transformation thus provides a better opportunity for low-temperature sintering of ZTA-powder compacts than the more conventional approach on the basis of $\alpha$-alumina.

After the alumina phase transformation, the compacts prepared from powders calcined at $800^{\circ}$ and $1200^{\circ} \mathrm{C}$ show different densification behavior. The compact prepared from powder calcined at $1200^{\circ} \mathrm{C}$ densifies at a much lower temperature than the compact prepared from powder calcined at $800^{\circ} \mathrm{C}$ (Fig. 2). Compacts prepared from powder calcined at $550^{\circ} \mathrm{C}$ do not sinter to full density at all (Table II). Obviously, the final sintering temperature decreases with increasing calcination temperature.

It cannot be ruled out that calcination at a temperature as high as $1200^{\circ} \mathrm{C}$ for $2 \mathrm{~h}$ resulted in $\alpha$-alumina nuclei, which because of their small amount could not be detected by X-ray diffraction. The formation of $\alpha$-alumina nuclei during calcination may affect later transformation and densification behavior. ${ }^{12-15}$ Although, on the basis of the difference in calcination temperature, different amounts of $\alpha$-alumina nuclei should be expected, the densification behavior of compacts prepared from powders calcined at either $1100^{\circ}$ or $1200^{\circ} \mathrm{C}$ did not show any difference. The influence of possible $\alpha$-alumina nuclei can thus be left out. Any explanation for the observed difference in densification behavior of the compacts prepared from powders calcined at $800^{\circ}$ and $1200^{\circ} \mathrm{C}$ should be found in a closer examination of the

Table II. Green Densities and Sintered Densities of Samples Prepared from ZTA Powders Calcined at Various Temperatures and Sintered at $1600^{\circ} \mathrm{C}$ for $2 \mathrm{~h}$

\begin{tabular}{rll}
\hline $\begin{array}{c}T_{\text {cak }} \\
\left({ }^{\circ} \mathrm{C}\right)\end{array}$ & $\begin{array}{c}\rho_{\text {gurcul }} \\
(\%)\end{array}$ & $\begin{array}{c}\rho_{\text {sinuced }} \\
(\%)\end{array}$ \\
\hline 550 & 33 & 71 \\
800 & 34 & 97 \\
900 & 34 & 97 \\
1000 & 36 & 98 \\
1100 & 39 & 98 \\
1200 & 40 & 98 \\
1200 & 40 & $96^{*}$ \\
1300 & 47 & 86 \\
\hline
\end{tabular}

* Sintered for $2 \mathrm{~h}$ at $1450^{\circ} \mathrm{C}$.

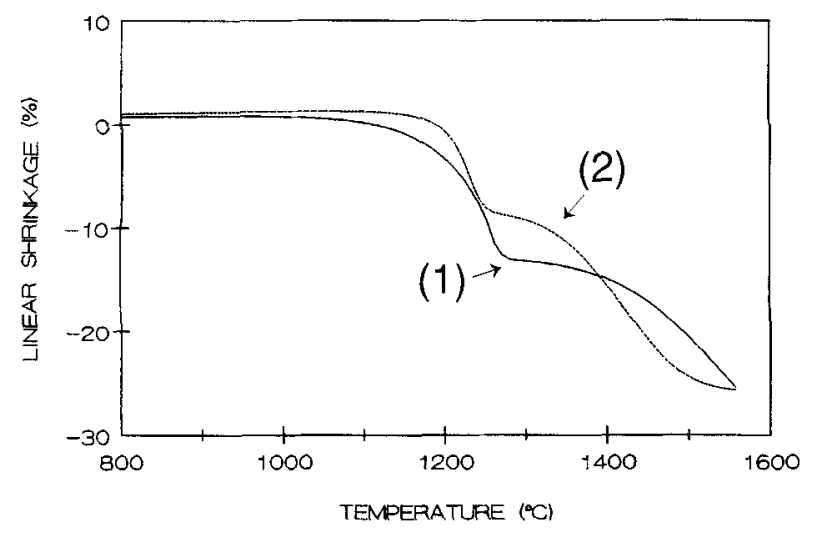

Fig. 2. Dilatometer curve of ZTA calcined at $800^{\circ} \mathrm{C}$ (1) and $1200^{\circ} \mathrm{C}$ (2). Heating rate $=2.5^{\circ} \mathrm{C} / \mathrm{min}$. microstructural development during densification and phase transformation.

Compacts prepared from powders calcined at $1200^{\circ} \mathrm{C}$ were also isothermally sintered at $1450^{\circ} \mathrm{C}$. A density of more than $95 \%$ of theoretical is obtained within $2 \mathrm{~h}$ (Table II). Scanning electron microscopy demonstrated that after this heat treatment a homogeneous microstructure of equiaxed, $1.0-\mu \mathrm{m}$ alumina grains was obtained. The zirconia is located on alumina grain boundaries and has a mean grain size of 0.3 to $0.4 \mu \mathrm{m}$.

To establish the influence of zirconia on the densification behavior, nonisothermal densification curves of both pure $\theta$-alumina and ZTA compacts prepared from powders calcined at $900^{\circ} \mathrm{C}$ are given in Fig. 3. According to the densification curves, the alumina phase transformation in powder compacts is shifted from $1170^{\circ}$ to $1240^{\circ} \mathrm{C}$ due to the presence of zirconia, which was confirmed by differential scanning calorimetry (DSC). The presence of zirconia, however, did not affect either the density directly after the transformation $(51 \%)$ or the shape of the densification curve after the alumina phase transformation.

The observation that the phase transformation always takes place when the macroscopic density reached $51 \%$, irrespective of calcination temperature or presence of zirconia, strongly suggests that a critical bulk density exists, above which the nucleation of $\alpha$-alumina is not kinetically hindered and the alumina phase transformation takes place.

\section{(4) Microstructural Development during Phase \\ Transformation}

The microstructural development during the $\theta$ - to $\alpha$-alumina phase transformation obviously is the most important step during the densification of transition alumina-containing composites. The microstructural development during phase transformation was investigated by heating samples to a temperature just before or after the phase transformation and by subsequent cooling to room temperature. Just before the alumina phase transformation, the nitrogen adsorption/desorption isotherms of compacts prepared from powder calcined at $800^{\circ} \mathrm{C}$ still show a hysteresis loop in the relative pressure range below 0.9 , representing intra-aggregate pores (Fig. 4). Apparently the aggregates did not sinter to full density during this stage of the sintering process.

After the phase transformation to $\alpha$-alumina, the isotherm in the relative pressure range below 0.9 still shows some hysteresis (Fig. 4). This observation is in accordance with Wefers and Misra, "who state that the aggregate structure of irregularly shaped transition alumina platelets separated by irregularly shaped pores may persist during the phase transformation to $\alpha$-alumina. The remaining hysteresis in the lower relative pressure range of the isotherm is ascribed to these pores.

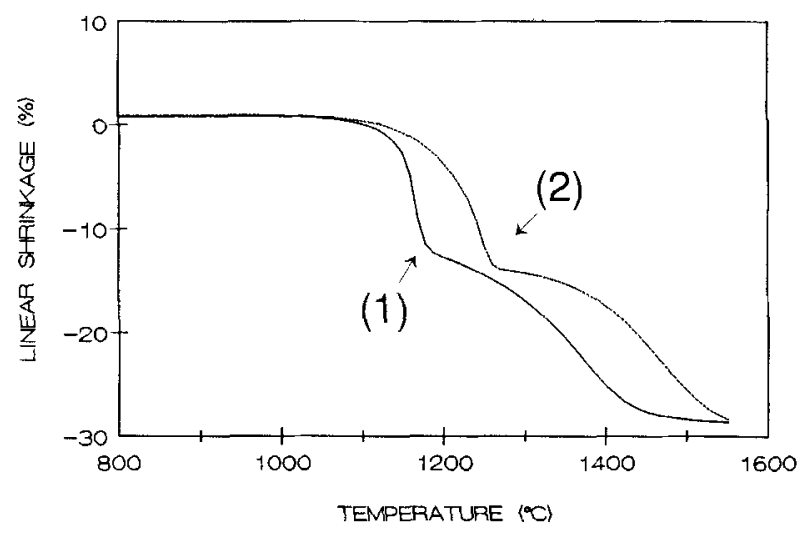

Fig. 3. Dilatometer curve of pure $\theta$-alumina (1) and ZTA (2). Calcination temperature $=900^{\circ} \mathrm{C}$, heating rate $=2.5^{\circ} \mathrm{C} / \mathrm{min}$. 


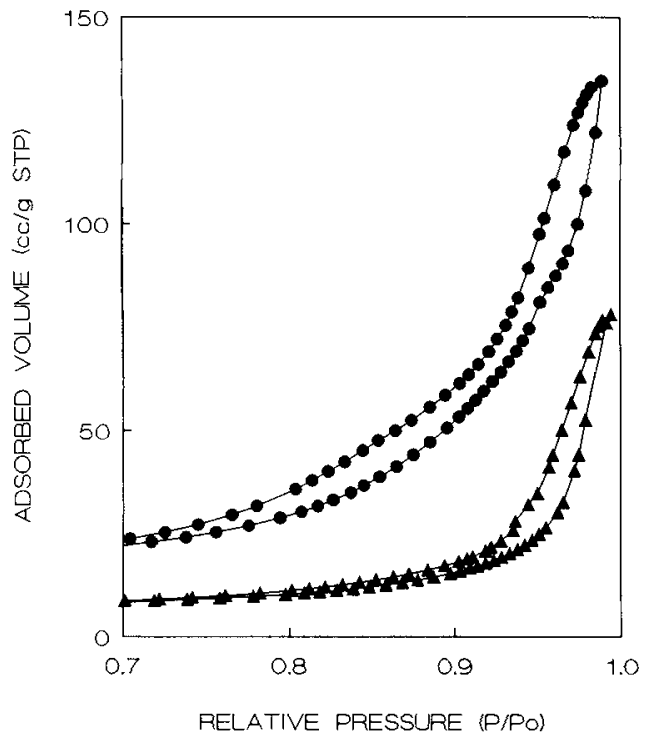

Fig. 4. Representative nitrogen adsorption-desorption isotherms on ZTA just before $(\mathbf{O})$ and directly after $(\boldsymbol{\Lambda})$ the alumina phase transformation $\left(T_{\text {calc }}=800^{\circ} \mathrm{C}\right)$.

Just before the alumina transformation, the adsorption/ desorption isotherm of the compact prepared from powder calcined at $1200^{\circ} \mathrm{C}$ showed no hysteresis which could be attributed to intra-aggregate pores, because the aggregates densified during calcination at $1200^{\circ} \mathrm{C}$.

In contrast with the compact prepared from a powder calcined at $1200^{\circ} \mathrm{C}$, considerable grain growth (from 6 to $34 \mathrm{~nm}$ ) and a drastic decrease in specific surface area (from 118 to 40 $\mathrm{m}^{2} / \mathrm{g}$ ) are observed in the compact prepared from powder calcined at $800^{\circ} \mathrm{C}$, during $\theta$-alumina matrix sintering (Table III). Apparently both observations are related to the densification of the porous $\theta$-alumina aggregates during sintering. Partial reduction of the specific surface area by pores' closing off and becoming undetectable by nitrogen adsorption, however, could not be completely ruled out. At the onset of alumina phase transformation $\left(T=1220^{\circ} \mathrm{C}\right)$, the compact prepared from powder calcined at $800^{\circ} \mathrm{C}$ still has a lower crystallite size and a higher specific surface area than the compact prepared from powder calcined at $1200^{\circ} \mathrm{C}$, supporting the idea that the porous $\theta$-alumina aggregates were still not completely densified at the onset of the phase transformation.

In the presence of zirconia, the alumina phase transformation takes place at a considerably higher temperature than in pure alumina (Fig. 3). The development of the pore size distribution of the pure alumina compact prepared from powder calcined at $900^{\circ} \mathrm{C}$, during the alumina phase transformation, however, proved to be identical to that observed for ZTA compacts prepared from powder calcined at the same temperature. It looks as though zirconia decreases the densification rate of the transition

Table III. Crystallite Sizes and Specific Surface Areas of Zirconia-Toughened Alumina after Isostatic Compaction, Prior to $\left(1220^{\circ} \mathrm{C}\right)$ and directly after the Phase Transformation to $\alpha$-alumina during Nonisothermal Sintering $\left(2.5^{\circ} \mathrm{C} / \mathrm{min}\right)$

\begin{tabular}{|c|c|c|c|c|}
\hline & $\begin{array}{l}T_{\text {: valc }} \\
\left({ }^{\circ} \mathrm{C}\right)\end{array}$ & Green compact & Prior to $\theta \longrightarrow \alpha$ & After $\theta \rightarrow \alpha$ \\
\hline $\begin{array}{l}\mathrm{ZrO}_{2} \text { crystallite } \\
\text { size }(\mathrm{nm})\end{array}$ & $\begin{array}{r}800 \\
1200\end{array}$ & 44 & $\begin{array}{l}43 \\
57\end{array}$ & $\begin{array}{l}50 \\
57\end{array}$ \\
\hline $\begin{array}{l}\mathrm{Al}_{2} \mathrm{O}_{3} \text { crystallite } \\
\text { size }(\mathrm{nm})\end{array}$ & $\begin{array}{r}800 \\
1200\end{array}$ & $\begin{array}{r}6 \\
37\end{array}$ & $\begin{array}{l}34 \\
47\end{array}$ & $\begin{array}{l}>100 \\
>100\end{array}$ \\
\hline $\begin{array}{c}\text { Specific surface } \\
\text { area }\left(\mathrm{m}^{2} / \mathrm{g}\right)\end{array}$ & $\begin{array}{r}800 \\
1200\end{array}$ & $\begin{array}{r}118 \\
35\end{array}$ & $\begin{array}{l}40 \\
22\end{array}$ & $\begin{array}{r}16 \\
8\end{array}$ \\
\hline
\end{tabular}

alumina aggregates; as a result, the assumed critical density at which the phase transformation takes place is reached at a later stage of the heating procedure.

The final sintering temperature of ZTA is related to the amount of densification of the transition alumina aggregates during calcination and sintering. Remaining porosity persists during the subsequent alumina phase transformation, thus giving rise to a microstructure which densifies only at a higher temperature. The higher sintering temperature is most likely to be caused by the presence of more irregularly shaped $\alpha$-alumina particles. In this paper it is demonstrated that, by means of a proper selection of the calcination temperature of gel-derived ZTA powders, a dense microstructure after sintering can be obtained which meets the requirements mentioned in the introduction.

\section{Conclusions}

$\mathrm{ZrO}_{2}\left(+3 \mathrm{~mol} \% \mathrm{Y}_{2} \mathrm{O}_{3}\right) / 85$ wt $\% \mathrm{Al}_{2} \mathrm{O}_{3}$ powders were prepared by the hydrolysis of metal chlorides. The powders mainly contain porous transition alumina aggregates of which the porosity decreases with increasing calcination temperature.

The densification behavior of the powder compacts can be characterized by a transition- and an $\alpha$-alumina densification stage, clearly separated by the alumina phase transformation.

The microstructural development during the transition alumina densification stage can be characterized by a further densification of the transition alumina aggregates.

When calcined at relatively low temperatures, the aggregates do not densify completely during the transition alumina densification stage. Remaining intra-aggregate porosity persists during the alumina phase transformation and negatively influences further densification.

Compacts prepared from powder calcined at $1200^{\circ} \mathrm{C}$ reach almost full density (96\%) after sintering for $2 \mathrm{~h}$ at $1450^{\circ} \mathrm{C}$, resulting in an alumina and a zirconia grain size of $1 \mu \mathrm{m}$ and $0.3-0.4 \mu \mathrm{m}$, respectively.

Acknowledgment: The authors wish to thank Prof. dr. ir. H. Verweij for his useful comments.

\section{References}

'N. Claussen, "Fracture Toughness of $\mathrm{Al}_{2} \mathrm{O}$, with an Unstabilized ZrO, Dispersed Phase," J. Am. Ceram. Soc., 59 [1-2] 49-51 (1976).

${ }^{2} \mathrm{E}$. Bischoff and M. Rühle, "Microcrack and Transformation Toughening of Zirconia-Containing Alumina"; pp. 635-43 in Advances in Ceramics, Vol. 24. Science and Technology of Zirconia III. Edited by S. Somiya, N. Yamamoto, and H. Yanagida. American Ceramic Society, Columbus, $\mathrm{OH}, 1988$.

${ }^{3}$ Y. Maehara and T. G. Langdon, "Superplasticity in Ceramies," J. Mater. Sci., 25, 2275-86(1990)

${ }^{4}$ J. C. Debsikdar, "Influence of Synthesis Chemistry on Alumina-Zirconia Powder Characteristics," J. Mater. Sci., 22, 2237-47 (1987).

${ }^{5} \mathrm{~J}$. P. Bach and F. Thévenot, "Fabrication and Characterization of ZirconiaToughened Alumina Obtained by Inorganic and Organic Precursors," J. Mater. Sci., 24, 2711-21 (1989).

${ }^{6}$ E. A. Pugar and P. E. D. Morgan, "Coupled Grain Growth Effects in $\mathrm{Al}_{2} \mathrm{O}_{3} /$ $10 \mathrm{vol} \% \mathrm{ZrO}_{2}$,"J. Am. Ceram. Soc., 69 [6] C-120-C- 123 (1986).

${ }^{7}$ H. Yoshimatsu, H. Kawasaki, and A. Osaka, "Stability of Tetragonal 7.rO, Phase in $\mathrm{Al}_{2} \mathrm{O}_{3}$ Prepared from $\mathrm{Zr}$-Al Organometallic Compounds," I. Mater. Sci., 23, 332-36 (1988).

${ }^{8} \mathrm{~J}$. McKittrick, G. Kalonji, and T. Ando, "Microstructural Control of $\mathrm{Al}_{2} \mathrm{O}_{3}-\mathrm{ZrO}_{2}$ Ceramics through Rapid Solidification"; see Ref. 2, pp. 267-75.

"G. Kalonji, J. McKittrick, and L. W. Hobbs, "Applications of Rapid Solidification Theory and Practice to $\mathrm{Al}_{2} \mathrm{O}_{3}-\mathrm{ZrO}_{2}$ Ceramics"; pp. 816-25 in Advances in Ceramics, Vol. 12, Science and Technology of Zirconia II. Edited by N. Claussen, M. Rühle, and A. Heuer. American Ceramic Society, Columbus, $\mathrm{OH}, 1984$.

${ }^{\mathrm{I}} \mathrm{S}$. Hori, M. Yoshimura, S. Sōmiya, and R. Takahashi, " $\mathrm{Al}_{2} \mathrm{O}_{3}-\mathrm{ZrO}$, Ceramics Prepared from CVD Powders"; see Ref. 9, pp. 794-805.

"P. A. Badkar and J. E. Bailey, "The Mechanism of Simultaneous Sintering and Phase Transformation in Alumina,"J. Mater, Sci., 11, 1794-806 (1976).

${ }^{12}$ M. Kumagai and G. L. Messing, "Enhanced Densification of Boehmite SolGels by $\alpha$-Alumina Seeding," J. Am. Ceram. Soc., 67 [11] C-230-C-231 (1984).

${ }^{13} \mathrm{~F}$. W. Dynys and J. W. Halloran, "Alpha Alumina Formation in AlumDerived Gamma Alumina," I. Am. Ceram. Soc, 65 [9] 442 448 (1982). 
${ }^{14}$ M. Kumagai and G. L, Messing, "Controlled Transformation and Sintering of a Boehmite Sol-Gel by $\alpha$-Alumina Seeding," J. Am. Ceram. Soc., $68[9] 500-$ $505(1985)$

${ }^{15} \mathrm{G}$. L. Messing and M. Kumagai, "Low-Temperature Sintering of Seeded Sol-Gel-Derived, $\mathrm{ZrO}_{2}$-Toughened $\mathrm{Al}_{2} \mathrm{O}_{3}$ Composites," J. Am. Ceram. Soc., 72 [1] $40-44$ (1989).

${ }^{16} \mathrm{~K}$. Wefers and C. Misra, "Oxides and Hydroxides of Aluminum"; Alcoa Technical Paper No. 19, Revised. Alcoa Laboratories, 1987.

${ }^{17}$ F. W. Dynys and J. W. Halloran, "Influence of Aggregates on Sintering," J. Am. Ceram. Soc., 67 [9] 596-601 (1984).

${ }^{14}$ M. A. C. G. Van de Graaf, J. H. H. Ter Maat, and A. J. Burggraaf, "Microstructure and Sintering Kinetics of Highly Reactive $\mathrm{ZrO}_{2}-\mathrm{Y}_{2} \mathrm{O}_{3}$ Ceramics," J. Mater. Sci., 20, 1407-18 (1985).

${ }^{10} \mathrm{H}$. Kruidhof, "The Determination of Small Amounts of Aluminum and Silicon in Stabilized Zirconia Ceramics," Anal. Chim. Acta, 99, 193-195 (1978).
2"K. P. Klug and L. E. Alexander, X-ray Diffraction Procedure for Polycrystalline and Amorphous Materials; ch. 9, pp. 618-708. Wiley, New York, 1974.

${ }^{21}$ J. C. Wurst and J. A. Nelson, "Lineal Intercept Technique for Measuring Grain Size in Two-Phase Polycrystalline Ceramics,"J. Am. Ceram. Soc., 55 [2] 109 (1972).

223. H. De Boer, "The Shapes of Capillaries"; pp. 68-94 in The Structure and Properties of Porous Materials, Proceedings of the Tenth Symposium of the Colston Research Society (Bristol, U.K., 1958). Edited by D. H. Everett and F. S. Stone. Butterworths Scientific Publications, London, U.K., 1958.

${ }^{2 .}$ P. den Exter, A. J. A. Winnubst and A. J. Burggraaf, "Sintering of ZTA at Low Temperatures through Transition Alumina Densification": pp. 1377-81 in Euro-Ceramics II, Vol. 2, Proceedings of the Second European Ceramic Society Conference (Augsburg, Germany). Edited by G. Ziegler and H. Hausner. Deutsche Keramische Gesellshaft, Köln, Germany, 1991. 